\title{
ARTICLE \\ Assessment of the Cause and Effect of Early Damage of Cobble Stone Road Construction and Its Remedial Measurements: A Case of Nekemte Town Cheleleki Sub City
}

\author{
Shiferaw Garoma Wayessa ${ }^{1^{*}}$ Ayana Abera Beyene ${ }^{2}$ \\ 1.Department of Civil Engineering, College of Engineering and Technology, Wollega University, Nekemte, Ethiopia \\ 2.Department of Surveying Engineering, College of Engineering and Technology, Wollega University, Nekemte, \\ Ethiopia
}

\section{ARTICLE INFO}

Article history

Received: 26 April 2021

Accepted: 6 May 2021

Published Online: 15 May 2021

Keywords:

Cobblestone road

Failures

Remedial measures

Laboratory test

\begin{abstract}
Road constructing in Ethiopia is increasingly in demand to meet its medium and long term development programs. Most internal roads of Oromia city/town are cobblestone and gravel. Some portions along the alignment proposed and existing roads traversed low resistance of the subgrade that affect the stability of the upper layers of cobblestones. Structural failure is observed on cobblestone roads, and it would be constructed with good quality or low quality of materials. Nekemte Cobblestones Projects have been started in 2014 widely which were filled in most areas today as we observed that needs to be addressed and a corresponding remedial measures must be drawn. A possible counteractive actions had been ordered for every observed destroyed to achieve the standard road situation of the study zone. An evaluation was made use observation, interviews, laboratory test and field test to govern an appropriateness of cobblestones. The lie beneath soil used for bottom layers of road structure based on standard of Ethiopian Road Authority (ERA) low volume road standards. Therefore, result from the field test and laboratory test shown, causes of cobblestone road failures of Nekemte street segment were mostly because of the construction steps/sequence, quality of materials, road construction time, absence of appropriate design, quality supervisor, absences of drainage structures, lack of highly compaction, lack of accurately fill fine aggregate and suddenly high loads vehicle applied on cobblestone road.
\end{abstract}

The road segment joins managerial, monetary and ethnic centers in the area ${ }^{[11]}$.

Metropolitan infrastructures usually run within the town borders. The main objective of highway is organizations were delivering access within financial and lawmaking framework. Businesses were in demand highway for the gathering contributions and spreading goods to

*Corresponding Author:

Shiferaw Garoma Wayessa, Department of Civil Engineering, College of Engineering and Technology, Wollega University, Nekemte, Ethiopia;

Email: shiferawgaroma77@gmail.com 
customer, storage in addition other manufacturing services before other distribution systems of transportation. The government sector and road users were the key implementers of roads. Traffic police, fire brigade and ambulance are standby ${ }^{[2]}$.

In the meantime the commencement of sophistication, man had needed to travel from place to place. The human want to develop road construction in the worldwide and change to sophisticate technology like cobble construction. Cobblestones have been a popular choice for roads and sidewalks for developing and developed countries. Cobblestones are small to medium-sized rounded, square stones used as pavement material for roads and walkways. In English, word cobblestone is derived from cobble, a word which appeared in the 15th century toward define rounded rocks or stones ${ }^{[3]}$.

The cobbles were highly durable stones, usually granite or basalt. The cobblestones were set in sand or mortar. Sand permits the road gradually give to traffic, avoiding the cracking related to pavement. Streets paved through cobblestones had proven their strength and longevity by showing up through damaged available sections of paved roads throughout the world. The term cobble is a geological term used to define a stone of a particular size, which is almost two and a half to ten inches (64 to 256 millimeters) ${ }^{[6]}$.

Shapes of cobblestone roads be subject to the imagination of the workers whom considered roads and fixed the cobbles. Paving stone road building contains 3 stages, quarry manufacturing fresh; renovating the raw settees and placing the cobble. Even though, appropriate control was wanted in the $3^{\text {rd }}$ step, management among different participants were important in the $1^{\text {st }}$ and $2^{\text {nd }}$ stages. The boulder naturally did not have quality to be an ultimate materials for roads that necessitates more strong suit and toughness than it can offer ${ }^{[1]}$.

The supply even though the obtainability of basaltic stone in the entire country. Sandstone was more difficult to hold together. Furthermore, it did not have the volume to resist big loads. The achievement and durability of road project at the end of the day rests on the groundwork of the bed layers and the use of suitable bedding materials.

\subsection{Problem of Statement}

Today in Ethiopia and most $3^{\text {rd }}$ world countries cobblestone is the most preferable construction material for road construction ${ }^{[2]}$. But the cobblestone construction method in general has a problem throughout Ethiopia especially in Nekemte town as everybody knows. Any infrastructure construction has its own procedure. However, construction of cobblestone in Nekemte town is reversible; before constructions of drainage structures cobblestones have been constructed, compacting the surface before and after the cobble road construction is not properly done and it could not provide the nature of the slope for cobble stone bedding.

\subsection{Objective}

-To identify major causes of the different repetitive failures of the cobblestone road surface;

- To investigate and analyses the different cobblestones road failure types;

- To provide the procedure of cobble stone road construction and recommend mitigation measures based on the findings.

\section{Method and Material}

\subsection{Study Area}

Nekemte is located at $328 \mathrm{~km}$ West of Addis Ababa along the main road to Asosa, enclosing between $9^{\circ} 35^{\circ}$ 00 " to $9^{0} 36^{\prime} 00^{\prime \prime}$ north latitude and $36^{\circ} 11^{\prime} 57$ to " $36^{0} 21^{\prime}$ " 15 " east longitude at an average altitude of $2100 \mathrm{~m}$ above sea level. East Wollega zone, in which Nekemte is located forms a part of the mid central plateau physiographies unit.

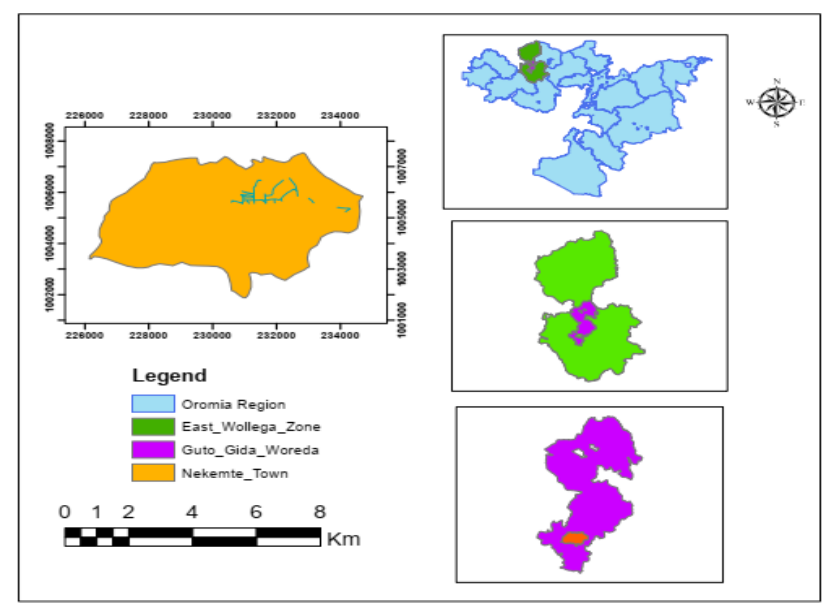

Figure 1. Location of study area

\subsection{Study Design}

Methodology follows in this study was included; questionnaire surveys, gather data and software based analysis to find appropriate mitigations beside all Nekemte town Cheleleki sub city cobblestone streets. Procedures of the study could be summarized as follows: site observation, surveying, data collection of questionnaires and interview, data analysis and presentation. 


\subsection{Method}

In the current study, principal and minor data are used. The primary data were collected from field surveys using laboratory test, questionnaires and interviews to measure the construction sequences in the study area. The primary data were collected from the Cheleleki sub city of Nekemte town using instruments to measure and digging out a sample of around location in the study zone. Whereas, the secondary data for the study were acquired from administrative institutions, reports, books, journals and the internet. The main data uses for this study were, design of cobblestones, construction of cobblestone, drainage structure, road users (public), consultant and contractors of in the study area.

\subsection{Materials}

The selected locations present in selected identified samples. Each sample was taken at $200 \mathrm{~m}$ distance by hand digging tool and the properties of the samples were investigated. For each sample, the classification rendering to the Unified Soil Classification, and American Association of State Highway and Transportation ${ }^{[9]}$. Statistical Package for Social Sciences, and it's used for various kinds of research data analysis. SPSS in this research was used to determine our data analysis

The other Material used is GPS. In the similar way, the satellite positions are known with great correctness. GPS receivers had clocks as well, but they were unstable and imprecise. Using the handheld GPS, location of cobble stones constructed the exact area of cobble stones damaged and area were constructed cobbles have errors would be collected.

\subsubsection{Process of Data Collection}

Process of data collection was delivered in different study areas. Few questionnaires and interviews were organized to collect the data from all highway user's public about the cobblestones construction procedure.

\subsubsection{Data Processing and Analysis}

Since all information to be collected was relevant/necessary, it was mostly done some data processing \& analysis. Data collected and analyzed in terms of tables, graphs, numbers and statements.

\section{Results and Discussion}

\subsection{Cobblestone Pavement}

Cobblestone surface contains fine aggregate placed right side and left side on sand soil. The term cobblestone was a physically denoting rock with a dimensions ranging from 5 to $25 \mathrm{~cm}$ in width. This roadway, frequently depend on stream stone was frequently used in earlier road European towns. The selected size of the cobblestone had an elongated diameter of 150 to $250 \mathrm{~mm}$ smaller diameter typically not below 50 to $100 \mathrm{~mm}$.

The boulder was placed through an elongated width in upright location through each boulder sited forcefully succeeding to each supplementary. The rock could be organized in shapes randomly. The connections situated typically filled through sand. The final surface was compacted using plate compactor or small roller. For roads in town zones, it was common exercised to fix the stone in bedding concrete.

Cobblestones should be basalt, properly uniform shape and color which free from cracked and other structural deficiencies or faults that would impair its essential reliability and of a level appearance.

Natural pigment differences that characteristic of the deposition source would be permitted. Cobblestones should be related to existing cobblestones on several downtown roads. The Nantucket Arrangement Board should submit samples for approval ${ }^{[8]}$.

Table 1. Stone dirt should conform to graduation requirements

\begin{tabular}{ccc}
\hline Sieve No & Sieve open & \% Passing \\
\hline № & 4 & 98 \\
№. & 50 & 88 \\
No. & 200 & 64 \\
\hline
\end{tabular}

\subsection{Compare and Contract Cobblestone Road Construction with Standard}

\subsubsection{Pre-Construction Survey}

It is a procedure for recording the pre-existing situations of a proposed road before building begins. To identify the start and end of the road development. It is a joined undertaking of the following parties: Government representatives, Contractor; and Consultants. In case of building of cobblestone road there is no leave-taking of the bodies of government representative and consultant. They are the same body that is suitable for dishonesties. 


\subsubsection{Successful Roadway Design}

Primary and constant community contribution throughout project, and the use of conception techniques aid the community, initial and throughout use multi criterial design group and the solicitation of flexible and creative design.

\subsubsection{Unsuitable Materials}

Materials comprising damage amounts of organic, for example grass, root \& sewerage. Organic soil peat and muck were not good for construction. Soils with LL exceeding $80 \%$ and PI, is greater than $55 \%$. Soil weight natural water content higher than 100 percent, Soil water very low usual density, $800 \mathrm{~kg} / \mathrm{m}^{3}$ or lower and Soils that could not be properly compacted.

Most construction of cobblestone in Nekemte contains the quantities of organic material like peat, muck and sewerage. The soils with liquid limit, plastic index and natural water content are exceeding the standard, because the cobblestones have been constructed during summer season. In case of improper compaction the soils very low natural density that is not recommended for construction of any types of roads.

\subsubsection{Requirement of Construction}

Earlier construction of embankment required clearing \& grubbing area should be performed. Embankment \& backfills should contain organic materials or other damaging substance were shown in the plans which surface of present ground should be compacted to a depth 150 mm.It provided on profile to show uppermost portions of the roadbed in both cut $\&$ fill, should contain of selected borrow for covering from quarries ${ }^{[7]}$.

\subsubsection{Method of Building Cobblestones}

When there was indication of inconsistencies arranged real altitudes that displayed on plan of construction. Investigation mentioned datum plan used in accepted design, should serve as origin for computation of the definite volume. As soon as fill was to be located \& trampled on hillsides or condensed against prevailing fills was built half width a time that existing slopes which were sharper than 3:1 should be constantly benched above areas as the work was carried up in layers.

Wherever an embankment less than $1.2 \mathrm{~m}$ below subgrade was to be made, all vegetable material should be removed \& cleared exterior should be scarified to a minimum deepness of the $150 \mathrm{~mm}$. Highway fill of soil materials should be located in straight layers not exceeding 200 $\mathrm{mm}$, moveable dimension \& should be compacted earlier the next layer was placed. Nevertheless, denser layer may be placed if vibratory roller high compaction strength used $\&$ providing the density necessity be obtained.

Effective distribution apparatus should be used to attain an identical depth as compaction of each layer growths, endless smoothing would be important to promise even density. Water should be additional or detached, if needing to acquire the mandatory density. After excavated material comprehends more than $25 \%$ quantity of stone larger than $150 \mathrm{~mm}$ the highest diameter \& couldn't be sited in layers different depth without severe or crushing such materials may be located on an fill in layers not exceeding in depth, but not greater than $600 \mathrm{~mm}$. Dumping (DT) \& rolling equipment shall be kept detached, and no lift.

\subsection{Discussions}

\subsubsection{Construction Methods of Cobblestones}

The sub base lower the stone dirt location bed should be well ordered and thoroughly compacted. Cobblestones should be wisely laid on stone dust location bed as shown on the plans, and should be dependably rammed in place by hand. The cobbles should be established with the elongated axis of each stone vertical to the roadway surface. The sets should be conventional such that each cobblestone was moving extra cobblestone.

The cobbles should be compacted and tamped with a mechanical plate compactor or another technique accepted by the board or its agent. Subsequently an adequate area of roadway has been laid. The highway surface should be verified with a 10 -foot straight edge and laid parallel with the centerline and any variations exceeding $12.5 \mathrm{~mm}$ should be adjusted and transported to proper grade. Any stone that becomes cracked throughout these procedures should be removed and replaced.

The cobblestones should be cleaned with a sand or cement mixture and muddled with water. The roadway surface should be shaken through a lightweight plate compactor to protect compaction between the joints. Additional joint filler of the sand or cement blend should be uniformly distributed as required to seal all of the voids. The process should be repeated for an extreme of 5 days till all the joints are full.

\subsubsection{Cobblestone Surface}

The rock exterior selection was used for country side road building where there was ready obtainability of rock material and it was appropriate for medium to high traffic thicknesses or where sections of the road have sharp longitudinal slopes. Stone developing may also deliver 
appropriate surface treatments for road sections through rural settlements and communities as well as market places. The pebble surface could be formed using the natural shape of the stone and assigning it. The joint would be filled with smaller fine aggregate. The stone surface could be produced by wounding stone keen on cubic or rectangular forms in command to guarantee that they were placed at tight pattern. Dressing gravels in this way means the final superficial would be smoother than the stone uses only its natural shape.

In both selections the gravels were put on a ready road sub base per a blinding layer of beach cushion about 50 $\mathrm{mm}$ between the steppingstones and the road sub-base layers. The gravel cushion houses irregularities in the sands, permitting the stones to be accumulated with a flat and level horse-riding surface. The stone surface was sheltered by a layer of fine aggregate filling gaps between the stones and providing a smoother riding surface for traffic. The aggregate surface option could be used as a road base course layer for surfacing.

\subsubsection{Material for Construction of Cobblestone}

Material for building the cobble surface consists of coarse stone, aggregate and fine aggregate. The minimum required characteristic of the material was described below:

\section{Stones}

The stone to be used for the roadway must be clean, hard, durable and free from clay. Gravels should be cubic or rectangular. The boulder should not be able to be cracked under the impact of compaction equipment. Round shape stone or river stones were not recommended for this purpose. The size of the rocks may vary depending on the functions of the gravels or as specified in the standard.

Stone for surface should be $150 \mathrm{~mm}$ x $250 \mathrm{~mm}$, with the smallest suitable size $100 \mathrm{~cm}$ x $150 \mathrm{~mm}$. Stone from a quarry should be dressed or shaped to the required shape when delivered to site. Curbstones from an excavation should be dressed to shape when delivered. The curbstones is crucial for holding the other stones in place. Small stones for filling the gaps should be $20 \mathrm{~mm} \times 30$ $\mathrm{mm}$ and $30 \mathrm{~mm} \times 50 \mathrm{~mm}$.

\section{Sand}

Sand from the pebble surface was used to accommodate any irregularities in the shape of the gravels allowing the stones to be assembled with a smooth and level equine surface. The sand was used as a drainage moderate for any water ingoing between the stones. The sand should be coarse sand either from a river or mountain sand must be clean, free of leaves, grass, compost, clay lumps, or dust etc.

\section{Gravel}

Gravel was used to fill gaps among stones to restrain the stones' movement when under traffic load.

The gravel also acts to provide a smooth running surface in the final layer. The gravel was rested over the stone surface and would seal the gaps. The gravel for this purpose could be highland gravel or river gravel should be well graded. The maximum size of the gravel, however, should not be greater than $5 \mathrm{~cm}$ and must be clean, free of leaves, grass, compost, clay lumps etc.

\subsubsection{Work Stages}

\section{Stage 1: Setting Out}

The cross section should be set for every $5 \mathrm{~m}$ interval. Mark the finished level of the stone surface in the center line and transfer with the design crown to edge pegs. The crown from the centerline to the edge Pegs should be $4 \%$ to $5 \%$. The width of the base should be $250 \mathrm{~mm}$ to 300 $\mathrm{mm}$ and depth should be $150 \mathrm{~mm}$ to $200 \mathrm{~mm}$. Bed level of, the foundation of both ends should be checked using a line level to guarantee they were at the same level. Position curbstones in the quarried foundation in upright position by keeping the top level of the stone as fixed in the peg. Back fill the curbstones with gravel and deliver compaction by hand hammer.

\section{Stage 2: Blinding Course}

Prepare the road sub-base by shaping the sub-base level and ensuring 4 percent to $5 \%$ camber. Compact the arranged sub-base, then place and spread the blinding course layer of coarse sand of $50 \mathrm{~mm}$ thickness.

\section{Stage 3: Placing Stone}

Ensure the string line was stiffened at the noticeable levels and linked from edge peg to centerline peg. Place the stones on the spread sand as close organized as possible. Where some gravels are slightly wedge-shape, it was needed to place the wide end down onto the sand layer. The stones should be placed starting from the outside edge and then working towards the centerline of the road. Safeguard the top level of the gravels was at the level agreed by the rope line. Wherever the top level of the stone was advanced than the set string line, such stones should be hammered down into the sand to level. After the 
huge stones were placed, it was important to used small stones to stiffen the larger stones by introducing the small gravels into gaps between the large stones. The laying of the stone surface necessary skillful labor to attain good workmanship ${ }^{[10]}$.

\section{Stage 4: Surface Gravelling and Compaction}

To avoid movement of the stone, a thin layer of sand was spread over the stone surface and washed into the voids by broom. In order to make the stone surface waterproof and to deliver a smoother surface for vehicles. A thin layer $50 \mathrm{~mm}$ of selected gravel should cover the stone paving. The selected gravel had to contain mixture sand and coarse aggregate grading not larger than $5 \mathrm{~cm}$ with a small portion of clay. Some portions of the fine aggregate would be filled the stones gaps to further strengthen the stability of the stones and other fine aggregate would remain on the surface. The compaction would level the height of the stones providing a smoother surface on the carriageway. The compaction should be carried out from the road edge towards the centerline of the road ${ }^{[5]}$.

\section{Stage 5: Constructing Road Shoulder}

Road shoulders should be filled using mountain gravel or leatherette. Before filling, the present shoulder should be watered. The filled material was spread to form a slope of 7 percent to 8 percent away from the road. Compaction was then carried out by vibrating roller or plate compactor/vibrating tamper.

\section{Stage 6: Constructing Filter Drain}

Filter drains were constructed to drain water from surface of road to ditches. The filter drains should be constructed at the time of filling road shoulders by excavating the drain across the road shoulders in rectangular shapes of $20 \mathrm{~cm}$ to $30 \mathrm{~cm}$ varied with the overturn. The bottom level of the drain the same as the bottom level of the curbstones and oblique slightly away from the road. Compaction can then be begun at the time of compacting for road shoulders.

\section{Stage 7: Slope Protection}

The road shoulders and grades should be protected from erosion by planting grass and turning. The roots of the grass could help to retain the soil and stabilize the slopes and shoulders by preventing the surface soil from being washed away.

\subsubsection{Control Quality of Cobblestone}

The building of sett roadway included the selection, testing of materials, preparation and settlement of stone. Quality control and testing for these worked include checking the suitability of the materials. Some of these tests could be carried out in the field, but certain tests

Table 2. Resolve LL \& PL of Soil

Resolve of Liquid Limit \& Plastic Limit of Soil

TEST METHOD:AASHTO T89

\begin{tabular}{|c|c|c|c|c|c|c|}
\hline Determination & & & id Limit & & & \\
\hline Number of blows & & 32 & 27 & & & \\
\hline Test & No & 1 & 2 & 3 & 1 & 2 \\
\hline Container & & B1 & A3 & D1 & A & D4 \\
\hline Wt. of container + wet soil, & (g) & 53.20 & 49.80 & 48.22 & 24.21 & 24.23 \\
\hline Wt. of container + dry soil, & $(\mathrm{g})$ & 44.30 & 41.50 & 40.20 & 22.80 & 22.80 \\
\hline Wt. of container, & (g) & 17.70 & 17.40 & 17.60 & 17.76 & 17.68 \\
\hline Wt. of water, & (g) & 8.90 & 8.30 & 8.02 & 1.39 & 1.43 \\
\hline Wt. of dry soil, & (g) & 26.60 & 24.10 & 22.60 & 5.06 & 5.12 \\
\hline Moisture container, & $(\%)$ & 33.5 & 34.4 & 35.5 & 27.5 & 27.9 \\
\hline Average & & $\begin{array}{l}(\%) \\
34.46\end{array}$ & & & 28 & \\
\hline
\end{tabular}


should be carried out in a laboratory test.

\subsection{Laboratories Test}

\subsubsection{Atterberg's Limit Test}

The Plasticity of base and sub base materials were found to be non-plastic and to seal and subgrade materials are shown in the table below.

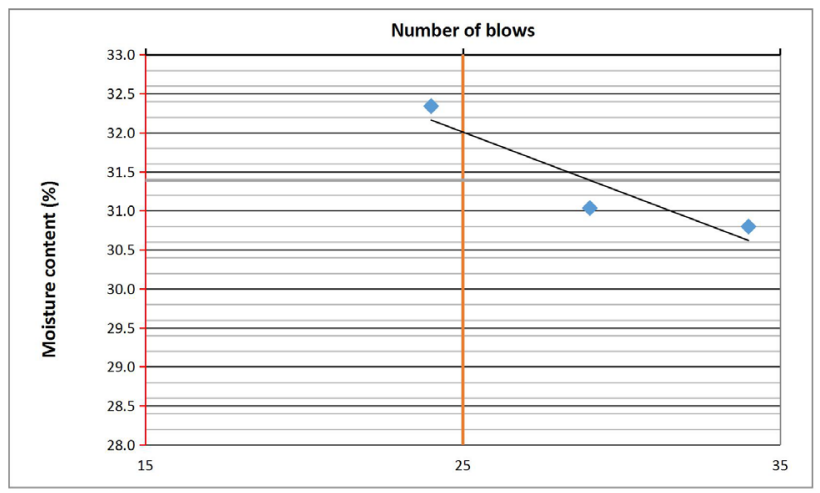

Figure 2. Moisture Content
Table 3. Determination of linear shrinkage

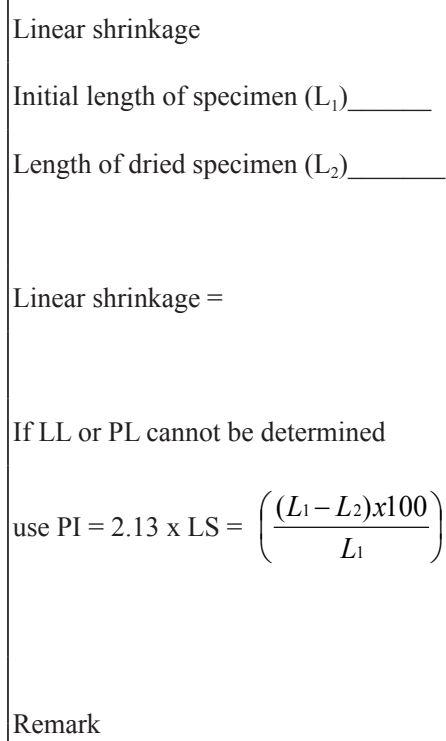

If LL or PL cannot be determined use PI $=2.13 \times \mathrm{LS}=\left(\frac{\left(L_{1}-L_{2}\right) x 100}{L_{1}}\right)$

Remark

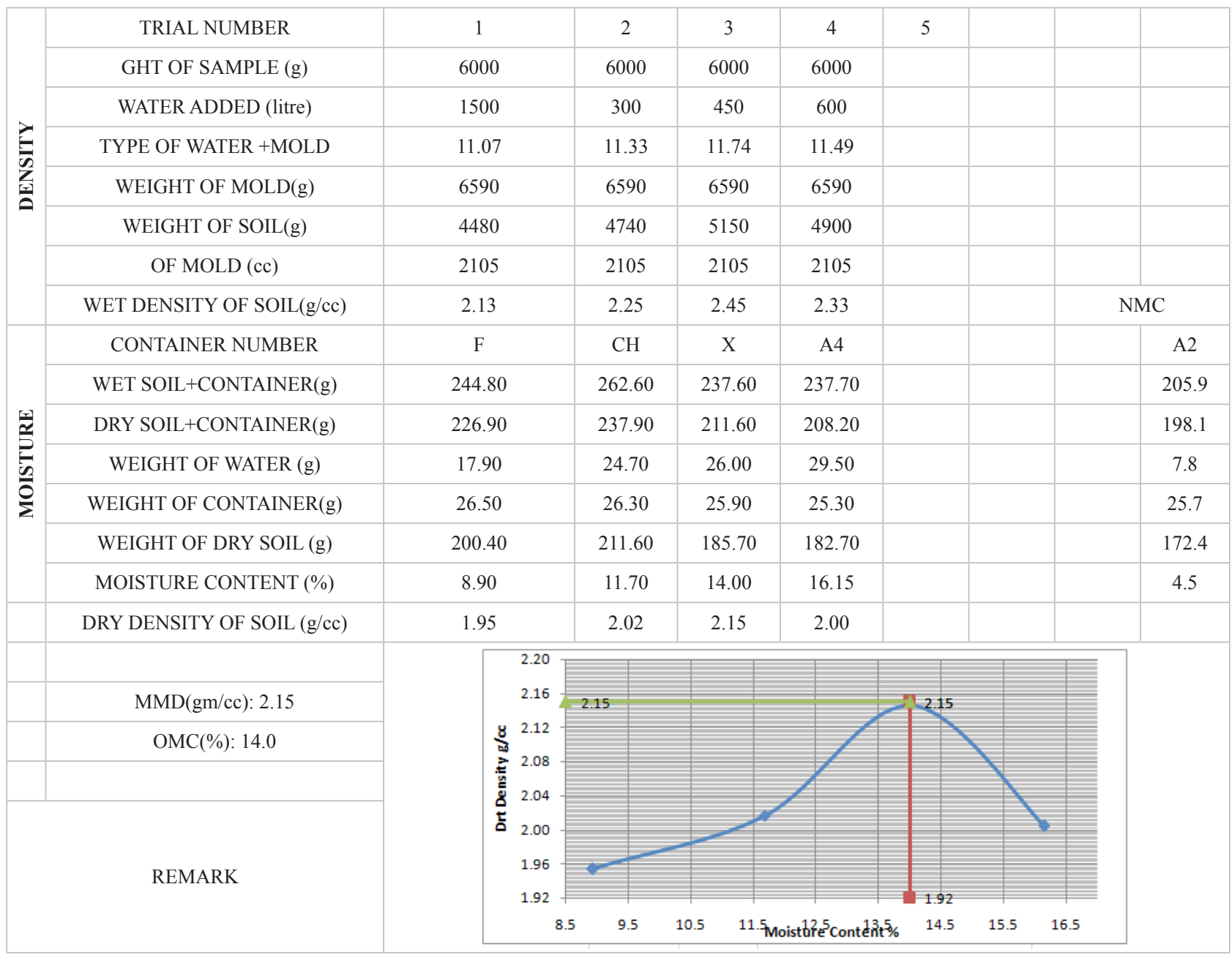

Figure 3. Moisture content density 
Table 4. Plastic Index

\begin{tabular}{|c|c|c|c|c|c|c|}
\hline $\begin{array}{c}\text { Determination } \\
\text { of }(P I) \\
(L L-P L)\end{array}$ & & & \multicolumn{4}{|c|}{ Grading } \\
\hline \multirow{2}{*}{} & - & LL & 34 & ASTM SIEVE NO & 10 & 40 \\
\cline { 2 - 7 } & - & PL & 28 & Dim. mm & 2.00 & 0.425 \\
\cline { 2 - 7 } & PI & 7 & $\%$ passing & & \\
\hline \multirow{2}{*}{ Plastic Product } & & & $\begin{array}{c}\text { AASHTO Soil } \\
\text { Classification }\end{array}$ & & \\
\hline
\end{tabular}

\subsubsection{Moisture Density Test}

The dry density values on the $y$-axis and the moisture contents on the $\mathrm{x}$-axis were schemed. And a smooth curve connect the designed points was drawn

\subsubsection{California Bearing Ratio Test}

The test outcomes from the small deterioration, medium worsening and high deterioration of road sections were listed in Tables. Based on test outcomes, the values designated that the materials used for all the three situations have very good CBR values when compacted at their maximum dry density and peak moisture content excluding sub base materials. The summary of the test result is tabulated below and the laboratory test analysis and plots are given in Table.

Table 5. California Bearing Ratio Test

\begin{tabular}{|l|l|l|l|}
\hline \multicolumn{2}{|l|}{ California Bearing Ratio Test } \\
\hline \multicolumn{2}{|l|}{ Test Method :AASHTO T-193 } & Nekemte Town & \multicolumn{2}{l|}{ Sample Taken From } & sub city \\
\hline Source Station & Nekemte Sub city & Date Sampled & \\
\hline Represented Section & Granular material & Date And Time Soaked & \\
\hline Material Description & Sub base & Date And Time Tested & \\
\hline Puropse & & Lab No. & \\
\hline Depth & & \\
\hline
\end{tabular}

\begin{tabular}{|c|c|c|c|c|c|c|}
\hline \multicolumn{7}{|c|}{ DENS ITY DE TERM I NAT I ON } \\
\hline \multirow{2}{*}{\multicolumn{2}{|c|}{ SOAKING CONDITION }} & \multirow{2}{*}{\begin{tabular}{|l}
10 Blows \\
AFTER
\end{tabular}} & \multicolumn{2}{|l|}{30 Blows } & \multicolumn{2}{|l|}{65 Blows } \\
\hline & & & BEFORE & AFTER & BEFORE & AFTER \\
\hline MOLD NUMBER & & M-8 & \multicolumn{2}{|l|}{ Z-5 } & \multicolumn{2}{|l|}{ B-7 } \\
\hline WEIGHT OF SOIL + MOLD(g) & $\mathrm{W}_{1}$ & 13540 & 12170 & 12400 & 13210 & 13260 \\
\hline WEIGHT OF MOLD (g) & $\mathrm{W}_{2}$ & 8000 & 6700 & 6700 & 7460 & 7460 \\
\hline VOLUME OF MOLD $\left(\mathrm{cm}^{3}\right)$ & V & 2266 & 2266 & 2266 & 2266 & 2266 \\
\hline WEIGHT OF WET SOIL (g) & $\mathrm{W}_{3}=\mathrm{W}_{1}-\mathrm{W}_{2}$ & 5540 & 5470 & 5700 & 5750 & 5800 \\
\hline WET DENSITY OF SOIL (g/cm³) & $\mathrm{W}_{\mathrm{d}}=\left(\mathrm{W}_{3} / \mathrm{V}\right)$ & 2.44 & 2.41 & 2.52 & 2.54 & 2.56 \\
\hline DRY DENSITY OF SOIL (g/cm³) & $\mathrm{D}_{\mathrm{d}}=\mathrm{W}_{\mathrm{d}} /(100+\mathrm{m}) * 100$ & 2.11 & 2.11 & 2.18 & 2.21 & 2.22 \\
\hline
\end{tabular}




\begin{tabular}{|c|c|c|c|c|c|c|c|c|c|}
\hline \multicolumn{10}{|c|}{ M O IS T URE D E T ERM I NAT I ON } \\
\hline \multirow{3}{*}{\multicolumn{2}{|c|}{ SOAKING CONDITION }} & \multicolumn{3}{|l|}{10 Blows } & \multirow{2}{*}{\multicolumn{2}{|c|}{\begin{tabular}{|l} 
30 Blows \\
AFTER
\end{tabular}}} & \multicolumn{3}{|l|}{65 Blows } \\
\hline & & \multirow{3}{*}{\begin{tabular}{|l} 
BEFORE \\
E
\end{tabular}} & \multicolumn{2}{|l|}{ AFTER } & & & \multirow{2}{*}{ BEFORE } & \multicolumn{2}{|l|}{ AFTER } \\
\hline & & & TOP 1 in. & AVG & TOP 1 in. & AVG. & & TOP 1 in. & AVG. \\
\hline CONTAINER NUMBER & & & Y & & $\mathrm{H}$ & & A3 & A4 & \\
\hline WET SOIL + CONTAINER (g) & a & 285.8 & 237.2 & & 265.7 & & 247.4 & 241.6 & \\
\hline DRY SOIL + CONTAINER $(\mathrm{g})$ & $\mathrm{b}$ & 254.0 & 208.0 & & 234.0 & & 219.0 & 213.0 & \\
\hline WEIGHT OF CONTAINER ( $\mathrm{g}$ ) & c & 26.0 & 25.8 & & 26.2 & & 25.8 & 25.3 & \\
\hline WEIGHT OF WATER ( $\mathrm{g}$ ) & $d=a-b$ & 31.8 & 29.2 & & 31.7 & & 28.4 & 28.6 & \\
\hline WEIGHT OF DRY SOIL ( g) & $\mathrm{e}=\mathrm{b}-\mathrm{c}$ & 228 & 182.2 & & 207.8 & & 193.2 & 187.7 & \\
\hline MOISTURE CONTENT ( \%) & $\mathrm{m}=(\mathrm{d} / \mathrm{e})^{*} 100$ & 13.9 & 16.0 & & 15.3 & & 14.7 & 15.2 & \\
\hline AVG. MOIST. CONTENT (\%) & & & & & & & & & \\
\hline
\end{tabular}

\begin{tabular}{|c|c|c|c|c|c|c|c|c|c|c|c|}
\hline \multicolumn{12}{|c|}{ PENETRATION TEST DATA } \\
\hline \multirow{2}{*}{\begin{tabular}{|l} 
PENETRATION \\
$(\mathrm{mm})$
\end{tabular}} & \multicolumn{4}{|c|}{10 Blows } & \multicolumn{3}{|l|}{30 Blows } & \multicolumn{4}{|l|}{65 Blows } \\
\hline & $\begin{array}{l}\text { DIAL } \\
\text { RDG }\end{array}$ & $\begin{array}{l}\text { LOAD } \\
(\mathrm{kn})\end{array}$ & $\begin{array}{l}\text { COR. LOAD } \\
(\mathrm{kn})\end{array}$ & CBR \% & DIAL RDG & $\begin{array}{l}\text { LOAD } \\
(\mathrm{kn})\end{array}$ & CBR \% & DIAL RDG & LOAD (kn) & $\begin{array}{l}\text { COR LOAD } \\
(\mathrm{kn}))\end{array}$ & CBR \% \\
\hline 0 & 0 & & & & 0 & 0 & & 0 & 0 & & \\
\hline 0.64 & 388 & & & & 396 & 1.81 & & 1400 & 6.38 & & \\
\hline 1.27 & 600 & & & & 990 & 4.51 & & 1800 & 8.21 & & \\
\hline 1.96 & 710 & & & & 1043 & 4.76 & & 2000 & 9.12 & & \\
\hline 2.54 & 824 & & 3.76 & 28.15 & 2030 & 9.26 & 69.3 & 2240 & 10.21 & 10.21 & 76.5 \\
\hline 3.18 & 900 & & & & 2180 & 9.94 & & 2330 & 10.62 & & \\
\hline 3.81 & 994 & & & & 2230 & 10.17 & & 2450 & 11.17 & & \\
\hline 4.45 & 1016 & & & & 2260 & 10.31 & & 2490 & 11.35 & & \\
\hline 5.08 & 1034 & & 4.72 & 23.66 & 2290 & 10.44 & 52.4 & 2660 & 12.13 & 12.13 & 60.6 \\
\hline 7.62 & 1064 & & & & 2350 & 10.72 & & 2990 & 13.63 & & \\
\hline 10.16 & 1084.0 & & & & 2460.0 & 11.218 & & 3168.0 & 14.45 & & \\
\hline 12.7 & & & & & & & & & & & \\
\hline
\end{tabular}


Journal of Building Material Science | Volume 03 | Issue 01 | June 2021

\begin{tabular}{|c|c|c|c|c|c|}
\hline \multicolumn{3}{|l|}{ SWELL } & \multirow[t]{2}{*}{ RING FACTOR } & \multirow{2}{*}{$\operatorname{MDD}(\mathrm{gm} / \mathrm{cc})$} & \multirow{2}{*}{2.17} \\
\hline No. OF BLOWS & 30 & 65 & & & \\
\hline RDG (BEFORE SOAKING) & 0.00 & 0.00 & \multirow{4}{*}{4.56} & \multirow{2}{*}{$\mathrm{OMC} \%$} & \multirow{2}{*}{10.8} \\
\hline RDG (AFTER) SOAKING) & 0.83 & 0.49 & & & \\
\hline PERCENT SWELL & 0.71 & 0.42 & & \multirow{2}{*}{$95 \%$ of MDD } & \multirow{2}{*}{2.06} \\
\hline AVERAGE PERCENT SWELL : \% & \multicolumn{2}{|c|}{0.76} & & & \\
\hline
\end{tabular}

\begin{tabular}{|c|c|c|c|c|c|c|c|c|c|}
\hline \multirow{2}{*}{ Blows } & \multicolumn{2}{|c|}{$\operatorname{LOAD}(\mathrm{KN})$} & \multicolumn{2}{|c|}{ CBR $(\%)$} & \multirow{2}{*}{$\begin{array}{c}\text { SWELL } \\
\%\end{array}$} & \multirow{2}{*}{\multicolumn{4}{|c|}{ DRY DENSITY Vs SOCKED C.B.R. }} \\
\hline & $2.54 \mathrm{~m}$ & $5.08 \mathrm{~m}$ & $2.54 \mathrm{~m}$ & $5.08 \mathrm{~m}$ & & & & & \\
\hline 10 & & 4.72 & 28.1 & 23.7 & 1.13 & No \# OF BLOWS & 10 & 30 & 65 \\
\hline 30 & & 10.44 & 69.3 & 52.4 & 0.71 & DRY DENSITY & 1.97 & 2.11 & 2.21 \\
\hline 65 & & 12.13 & 76.5 & 60.6 & 0.42 & SOCKED C.B.R. & 28.1 & 69.3 & 76.5 \\
\hline
\end{tabular}
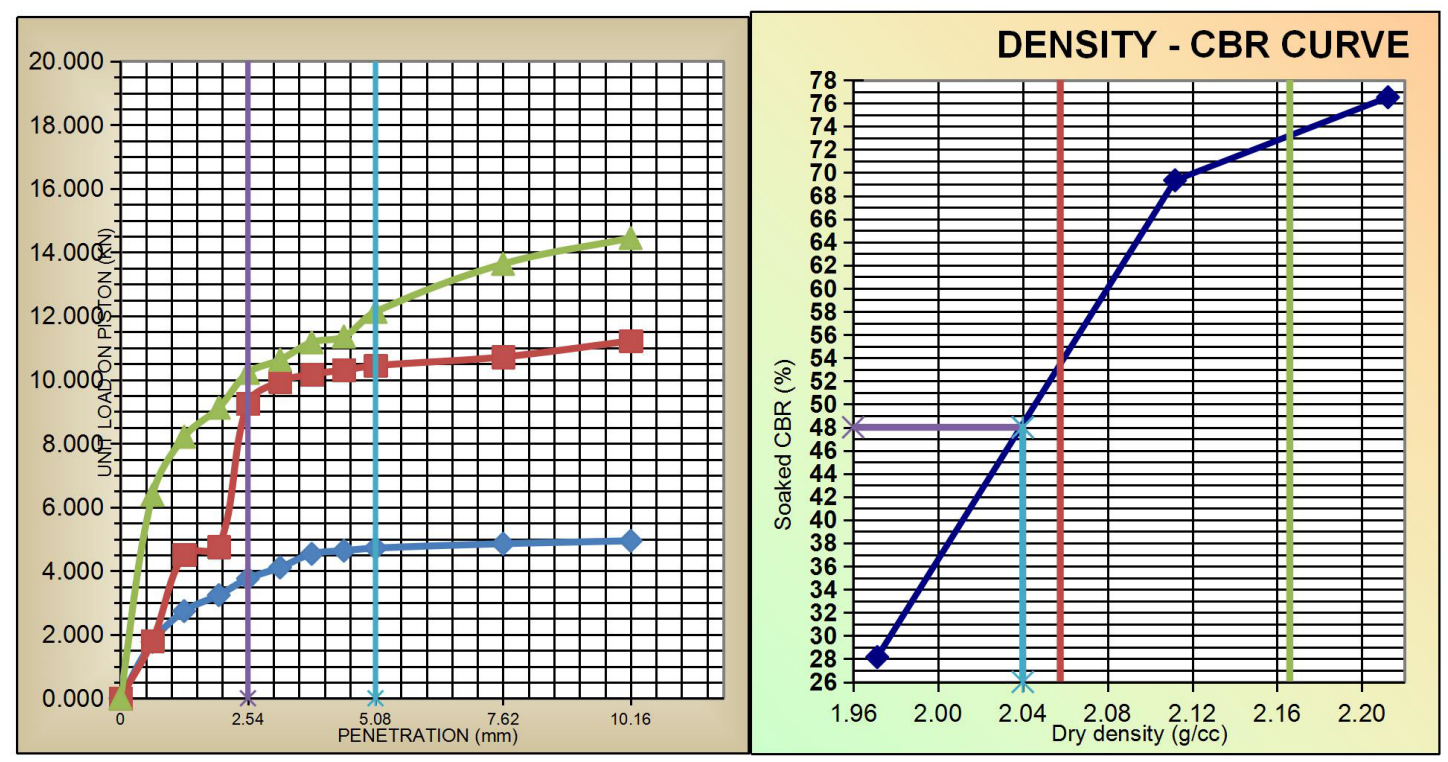

Figure 4. Stress vs. Penetration relationship for base course material

\begin{tabular}{|l|l|}
\hline \multicolumn{2}{|l|}{ MODIFIED PROCTOR : T 180} \\
\hline MDD (g/cc) : & 2.17 \\
\hline OMC (\%) : & 10.80 \\
\hline $95 \%$ of MDD $(\mathrm{g} / \mathrm{cc})$ & 2.06 \\
\hline CBR@ $95 \%$ of MDD & $\mathbf{4 8}$ \\
\hline
\end{tabular}

\subsection{Causes of Failure}

Traffic, and shoulder material have been worn away by Eroded by water. Settlement and Carriageway have been repaved leaving the shoulder surface at lower level Cause by Grass, weeds and bushes have been allowed to grow. This Result Surface water cannot flow directly from the carriageway to the roadside ditch. Silts accumulate at the edge of the carriageway. Deflection of the road centerline 
and shoulder. Deterioration of the road surface and destroyed without service. Distress on the road throughout cross section and road component. Sight distance from road users impaired, reducing road safety and increasing risk of accidents to person and animals.

\section{Conclusions}

Structural failure is observed on cobblestone roads, and it would be constructed with good quality or low quality of materials. Nekemte Cobblestones Projects have been started in 2014 widely which were failed in most areas today as we observed that needs to be addressed and a corresponding remedial measures must be drawn. A probable remedial actions have been organized for all experiential failure or demolished to gain regular road protest of the study area.

An assessment was made by using statement, meetings, laboratory test and field test to control the appropriateness of the cobblestones, motivated material to assist as a subgrade for road building based on project specifications and Ethiopian Road Authority (ERA) low volume road Specification. From the field tests and laboratory tests carried out, it was observed that the causes of cobblestone road failures of this road section are mainly due to the construction steps/sequence, quality of materials, road construction time, lack of proper design and quality control, absences of drainage structures, lack of highly compaction, lack of accurately fill fine aggregate and suddenly high loads vehicle applied on cobblestone road.

\section{References}

[1] Era Manual of Design Manual for Low Volume Roads and Road Maintenance Booklet - Part G Final Draft, August 2011.
[2] Professor Abebe Dinku.2010, Addis Ababa University's Institute of Technology. Cobblestone construction grows in Ethiopia despite concerns over quarry safety and the assessment study was supposed to have been conducted before the implementation of the cobblestone project and at its completion.

[3] Staccioli, Romolo Augusto. 2003. The Roads of the Romans. Los Angeles: J. Paul Getty Museum.

[4] Northwestern University. Siege and Commune Collection. Photo \# 300: "Paris Boulevard with Barricade and Cannon." Accessed April 25, 2006.

[5] Manual, Pavement for Labour-based Road Construction, Timor-Leste, ILO \& Don Bosco 2015, ISBN: 978-92-2-130857-7.

[6] Komar, P.D., and Allan, J.C., 2010, "Design with Nature"strategies for shore protection-The construction of a cobble berm and artificial dune in an Oregon State Park.

[7] Theodros, G. G. (2014). A Rapid Desk Study: Afghanistan - Current Status and Future Prospects for the Construction Sector. United Kingdom: Crown Copyright.

[8] Nuhamin Getachew, Performance of Construction Consultants in Addis Ababa: A Study of Current Practices.

[9] ERA MANUAL 2016, PART D: CONSTRUCTION OF LOW VOLUME ROADS.

[10] City Realty Website. Cobblestone Lofts Webpage. Accessed April 25, 2006: http://www.cityrealty.com/ condos/building_iframe.php?lid=7197.

[11] Desert wide Website. Cobblestone Subdivision Webpage. Accessed April 25, 2006: http://www.desertwide.com/subdivisions/Phoenix_Cobblestone.shtml. 